\title{
Identifying the Predisposing Factors and Socioeconomic Impacts of Meningitis: Nigeria Example
}

\author{
Azukaego .N. Nnaji ${ }^{1}$, Daniel .N. Nnaji ${ }^{2}$ \\ ${ }^{I}$ DivineAid Initiative, Abuja, Nigeria \\ ${ }^{2}$ Total Health Trust Limited, Abuja, Nigeria \\ Corresponding Author: Azukaego .N. Nnaji
}

\begin{abstract}
Meningitis is an epidemic prone worldwide disease with severe consequences on lives, functionality and economic state of affected individuals, communities, nations and world at large. While Meningitis outbreaks have regressed in other regions, Sub Saharan Africa still battles with the disease. Nigeria is credited with a long history of Cerebrospinal Meningitis (CSM) epidemics with the worst occurring in 1996 with 11,717 deaths out of 109,580 recorded cases. Despite the seasonality and scope of the disease, (Meningitis belt), severe mortalities and morbidities trail its occurrence. The dearth of scholarly articles in this area of study notwithstanding the magnitude of the problem, is also worrisome. This study aimed at identifying the predisposing factors and socio-economic impacts of Meningitis in Federal Capital Territory (FCT), Nigeria.
\end{abstract}

Methods: A cross-sectional and descriptive study was conducted using quantitative and qualitative methods of data collection. It made use of semi structured questionnaire in conjunction with in depth interviews and Focus Group Discussions. Data was collected from 80 participants (53 for quantitative and 27 for qualitative), cutting across experts on meningitis at the three levels of Nigerian government, as well as non-experts at the community level.

Results: The study revealed that the four (4) most important predisposing factors of Meningitis include Weather $(+$ Heat) $(\mathbf{2 2 . 0} \%)$, overcrowding $(21.2 \%)$, poor sanitary condition $(\mathbf{1 6 . 8})$, and poverty (12.3). Also, four (4) most important socio-economic impacts identified were: Loss of lives (Mortality) (21.6\%), Economic burden (17.5\%), Permanent disability (Morbidity) (12.9\%); and Impoverishment and Loss of productivity (each $12.4 \%$ ). Morbidity and Mortality yielded 34.5\%.

Conclusion: Climatic conditions and socioeconomic factors were essentially found to be the predisposing factors of Meningitis, which leave behind severe negative socioeconomic impacts, especially morbidity and mortality. There was good understanding of these predisposing factors and socioeconomic impacts across board, as well as community levels of FCT, Nigeria.

Keywords: Meningitis, Predisposing factors, Socioeconomic impacts, Nigeria, Mortalities, Morbidities, Meningitis belt

\section{INTRODUCTION}

$\mathrm{M}$ eningitis is an epidemic prone worldwide disease with severe consequences on lives, functionality and economic states of affected individuals, communities, nations and world at large. Meningitis is prevalent in an area of subSaharan Africa in a group of countries known as the 'Meningitis Belt' which stretches from Senegal in the West to Ethiopia in the East. Nigeria lies on the west coast of Africa between latitudes $4^{\circ} 16^{\prime}$ and $13^{\circ} 53^{\prime}$ north and longitudes $2^{\circ} 40^{\prime}$ and $14^{\circ} 41^{\prime}$ east. It occupies approximately 923,768 square kilometers of land stretching from the Gulf of Guinea on the Atlantic coast in the south to the fringes of the Sahara Desert in the north. The territorial boundaries are defined by the republics of Niger and Chad in the north, the Republic of Cameroon on the east, and the Republic of Benin on the west. Nigeria is the most populous country in Africa and the 14th largest in land mass. Current population is estimated at 198 million people with more than half of that less than 30 years (NPC, 2018).

Nigeria has a tropical climate with wet and dry seasons associated with the movement of the intertropical convergence zone north and south of the equator. Its climate is influenced by the rain-bearing southwesterly winds and the cold, dry, and dusty northeasterly winds, commonly referred to as the Harmattan. The dry season occurs from October to March with a spell of cool, dry, and dusty Harmattan wind felt mostly in the north in December and January. The wet season occurs from April to September. The temperature in Nigeria oscillates between $25^{\circ} \mathrm{C}$ and $40^{\circ} \mathrm{C}$, and rainfall ranges from 2,650 millimeters in the southeast to less than 600 millimeters in some parts of the north,mainly on the fringes of the Sahara Desert. These weather elements greatly influence occurrence of Meningitis in Nigeria.

Economically, more than 100 million Nigerians live on less than USD 1 per day (NBS, 2012). This makes the socioeconomic impact of Meningitis very devastating with gross impoverishment, loss of lives and productivity. 


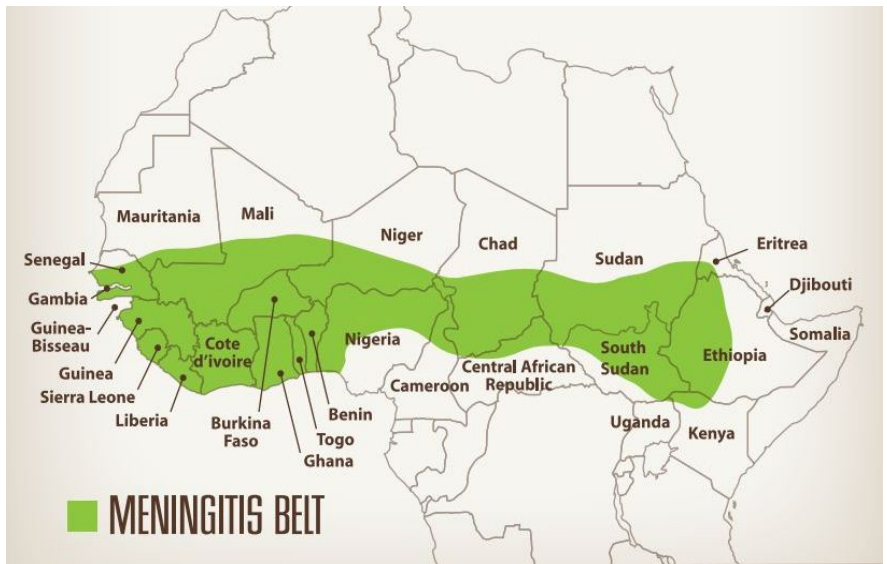

Figure 1. The African "Meningitis belt."

Source: ("Meningitis." Meningitis Vaccine Project. Web. 9 April 2018).

Meningitis is a worldwide disease (Jafri et al., 2013). However, it is disturbing that while outbreaks in other regions became less frequent, that in Africa became more common with associated mortalities and morbidities till date. Nigeria is credited with a long history of Cerebrospinal Meningitis (CSM). One of the worst occurred in 1996 when 109,580 cases and 11,717 deaths were recorded (Ogundipe and Obinna, 2017). Recently, in the year 2017: 14, 542 cases and 1,166 deaths were recorded with a case fatality ratio (CFR) of eight percent (NCDC, 2017). It is believed that regardless of the cause, an effective risk communication, and management will be highly instrumental in preparing both communities and the risk players in the management of this disease. When the communities know what to do; when the various stakeholders are adequately informed, this will be instrumental to reducing the spread, and socio-economic impacts observed.

Table 1: Case / death profile of Meningitis Epidemics in Nigeria from 1996 to 2019

\begin{tabular}{|c|c|c|}
\hline Year & Cases & Deaths \\
\hline 1996 & 109580 & 11717 \\
\hline 2003 & 4130 & 401 \\
\hline 2008 & 9086 & 562 \\
\hline 2009 & 9086 & 562 \\
\hline 2017 & 14542 & 1166 \\
\hline 2018 & 481 & 82 \\
\hline 2019 & 914 & 65 \\
\hline
\end{tabular}

Meningitis is caused by a variety of organisms but mostly bacteria which include, Streptococcus Pneumonia, Neisseria Meningitidis $(\mathrm{Nm})$, Haemophilus Influenzae and rarely, Lysteria Monocytogenes. However, several predisposing factors enhance the spread of the disease. The poverty level prevalent in sub-Saharan Africa is a huge factor which impacts negatively on its management through the existence of poor housing facilities with poor ventilation, overcrowding, poor environmental sanitation, very low per capita income (less than \$1 dollar a day) to mention but a few (Gudina et. al., 2016; NCDC, 2017).Though Meningitis is worldwide, the industrialized countries have been able to combat its menace by including different formulations (Jafri et al., 2013) in their vaccinations but this has eluded the African Meningitis belt due to poverty (Scarborough and Thwaites, 2008). It is of great concern that despite the seasonality and scope (Meningitis belt) of the disease, severe mortalities and morbidities trail its occurrence. Secondly, there is a dearth of scholarly articles in this area of study despite the magnitude of the problem. This study sought to identify the predisposing factors and socio-economic impacts of Meningitis in Nigeria.

\section{MATERIALS AND METHODS}

\section{Study Design and Setting}

The study was an applied research of the case study design involving a multi-method (literature review, qualitative and quantitative methods), cross sectional and descriptive method. It involved both primary and secondary data. The study population consisted of experts working at the federal, state, and Local Government levels (LGA); and non-experts such as women of child bearing age (15-45 years) as well as men at the community level. The study was conducted in Abuja, (Federal Capital Territory, FCT), the administrative capital city of Nigeria which is made up of six Area Councils (ACs), equivalent to Local Government Areas (LGA): ABAJI, AMAC, BWARI, KWALI, KUJE, and GWAGWALADA.

A combination of non-probability and probability sampling techniques was used. Non-probability sampling was used to identify the area, as well as the participants of study at the national, state and $\mathrm{AC}$ levels. The research employed stratification technique in selecting the sample units. First, Abuja as the federal capital and seat of power was conveniently and purposively selected. Random selection was used to select the area councils (three out of six): AMAC, BWARI and GWAGWALADA. For the community level data, two AC (AMAC and BWARI) out of the three ACs were randomly selected. The communities were stratified into urban and rural communities. One out of fifteen urban communities in AMAC, and one out of twenty rural communities in BWARI were randomly selected. Overall, 80 respondents were involved: 53 respondents in the survey, 7 key informants, and 20 Focus Group respondents.

\section{Data collection tools}

A pre-tested semi-structured questionnaire was used to obtain required information. Self-completion questionnaires were sent to the participants at the national, state and ACs. The questionnaires were accompanied with an introductory note, and consent. Participants were assured of anonymity of their responses. Key informant (KII) interview guide was used to obtain information from key informants while focus group 
(FGD) discussion guide was used to harness information from the FGDs. Literature reviews from earlier research and other relevant publications generated the secondary data. Main data sources for secondary information included: NCDC website, WHO website, UNISDR website, research gate, google scholar and University of Leicester library.

\section{Ethical Considerations}

The study was conducted under due consideration of the ethical principles governing social research like informed consent, confidentiality, deceit and lying in the course of research, disclosure, anonymity, and voluntary participation, avoiding harm and who to benefit. Ethical approval was granted by the FCT ethics committee before commencement of the research. Consent was obtained both verbally and in writing from all participants before data collection. To ensure anonymity, names of participants were not captured, neither were identities tagged to their quotes.

\section{Data Analyses}

Multiple techniques comprising of manual and computerbased applications were combined to analyze the quantitative and qualitative data generated by this study. All quantitative analyses were conducted using SPSS version 25 (IBM, NY, USA) and Microsoft Excel. Simple descriptive analysis involving frequency tables, were used. The qualitative data (field notes from the interviews (KIIs) as well as transcriptions from FGDs) were analyzed manually employing thematic analysis (using themes and sub-themesto allow for comparisons of views from the different respondents) in line with the objectives.

The instrument for data collection was pre-tested for reliability, validity and objectivity in one randomly selected Area Council before the main research.

\section{RESULTS}

\section{Characteristics of the study population}

A total of 53 people (29 male and 24 female) participated in the questionnaire survey. For the level of education, 31 attained tertiary level, 12 Master's level and 10 secondary school level. For the profession, 39 were public servants (work for government), 8 were self-employed (work for government part time) and 6 work for NGOs, and UN). For geographical distribution of the respondents, 15 work at national level, 5 state level and 33 AC level. 20 people participated in 2 FGDs (10 per FGD:1 urban and 1 rural), while 7 people participated in key informant interviews, making an overall total of 80 people.

Table 2. Socio-demographic Characteristics of the Participants

\begin{tabular}{|lcc|}
\multicolumn{4}{|c|}{ Socio-demographic Characteristics of the Participants } \\
\hline Characteristics & n & Percentage \\
\hline Gender & 29 & 54.7 \\
Male & 24 & 45.3 \\
Female & 53 & 100.0 \\
Total & &
\end{tabular}

\begin{tabular}{lcc|} 
Level of Education & & \\
Secondary level & 10 & 18.9 \\
Tertiary level & 31 & 58.5 \\
Master's degree level & 12 & 22.6 \\
Total & 53 & 100.0 \\
& & \\
Profession & 39 & 73.6 \\
Public servant (government) & 6 & 11.3 \\
Public servant (NGOs, CSOs, & & \\
UN etc) & 8 & 15.1 \\
$\begin{array}{l}\text { Public servant (self-employed } \\
\text { or entrepreneur) }\end{array}$ & 53 & 100.0 \\
Total & & \\
Geographical focus & 15 & 28.3 \\
National level & 5 & 9.4 \\
State level & 33 & 62.3 \\
Area council (LGA) & 53 & 100.0 \\
\hline Total & & \\
\hline
\end{tabular}

\section{Predisposing factors of Meningitis}

When the respondents, were asked to identify predisposing factors, the four (4) most important predisposing factors to Meningitis, identified in order of importance were: overcrowding (21.2\%), poor sanitary condition (16.8), weather (13.5), and poverty (12.3). Overall ranking for weather comes up to number 1 when heat $\left(7^{\text {th }}\right)$ which is an element of weather is added (weather + heat) giving $22.0 \%$. Other factors mentioned were infection $(10.3 \%)$, poor risk communication (10.3\%), and poor housing facilities (7.1\%).

Similar views also emerged from the KII and FGDs where all respondents cited same factors. $100 \%$ of FGD and KII respondents equally linked the first factor to weather element followed by overcrowding.

Table 3: Predisposing factors of Meningitis

\begin{tabular}{|llll|}
\hline \multicolumn{4}{|c|}{ Predisposing factors of Meningitis $(\mathbf{n = 5 3})$} \\
\hline Factors & Frequency & Percentage & Ranking \\
\hline Overcrowding & 33 & 21.2 & 1 \\
Poor sanitary condition & 26 & 16.9 & 2 \\
Weather & 21 & 13.5 & 3 \\
Poverty & 19 & 12.3 & 4 \\
Infection & 16 & 10.3 & 5 \\
Poor risk communication & 16 & 10.3 & 5 \\
Heat & 13 & 8.4 & 6 \\
Poor housing facilities & 11 & 7.1 & 7 \\
Total & 155 & 100 & \\
\hline
\end{tabular}

Note: Weather + heat $=34(22 \%)$

\section{Socioeconomic Impacts of Meningitis}

The research also explored the socio-economic impacts of Meningitis in Nigeria. Loss of lives (mortality) (21.6\%), Economic burden (17.5\%), Permanent disability (morbidity) 
(12.9\%); and Impoverishment and Loss of productivity (each $12.4 \%$ ) were the four (4) most important impacts identified. A combination of mortality and morbidity yielded $34.5 \%$. Other impacts mentioned were Stigma and Discrimination (11.9\%), Disruption of Social Structures (6.1\%), and Increased rate of malnutrition in children $(5.2 \%)$.

Similarly, from the KIIs and FGDs, responses supported the findings of the survey as impacts bordering on mortality and morbidity dominated the responses. Again $100 \%$ of the KII and FGD respondents mentioned morbidity and mortality as first impact. $50 \%$ of rural FGD respondents and $20 \%$ of urban FGD respondents attested having witnessed firsthand impairments of learning difficulties, sight, hearing, and behavioral problems in their children, relatives and neighbors.

Table 4: Socio-economic impacts of Meningitis

\begin{tabular}{|llll|}
\hline \multicolumn{4}{|c|}{ Socio-economic impacts of Meningitis (n=53) } \\
\hline Impact & Frequency & Percentage & Ranking \\
\hline Loss of lives (Mortality) & 42 & 21.6 & 1 \\
Economic burden & 34 & 17.5 & 2 \\
Permanent Disability & 25 & 12.9 & 3 \\
(Morbidity) & & & \\
Impoverishment & 24 & 12.4 & 4 \\
Loss of productivity & 24 & 12.4 & 4 \\
Stigma and Discrimination & 23 & 11.9 & 5 \\
Disruption of Social & 12 & 6.1 & 6 \\
Structure & & 5.2 & 7 \\
Increase rate of & 10 & & \\
Malnutrition in children & & 100 & \\
Total & 194 & & \\
\hline
\end{tabular}

Note: Mortality and morbidity $=67(34.5 \%)$

\section{DISCUSSION}

\section{Predisposing factors of Meningitis}

Occurrence of Meningitis is mostly attributed to Meningococcal bacteria (Nm) (NCDC, 2017; WHO, 2010), but certain factors predispose to its existence. Epidemics of Meningitis are a global problem and can touch any area in the world in spite of the climate (Umaru et al., 2013). However, Meningitis is prevalent in a group of countries in sub-saharan Africa known as the 'Meningitis belt' characterized by dry and dusty environment, low relative humidity, low rainfall (300-1100 mm mean rainfall), and high temperature (heat), in addition to socioeconomic factors such as poverty, poor living conditions (overcrowding, poorly ventilated houses, poor personal hygiene and environmental condition). According to this research, the four (4) most important predisposing factors to its occurrence include overcrowding, poor sanitary condition, weather, and poverty (socioeconomic and climate related factors). There was no particular pattern or relationship observed between variables like sex, age, geographical focus and level of education with the predisposing factors when cross tabbed. This is likely due to the fact that the respondents were allowed multiple responses and the responses were ranked according to the frequencies observed.

Factors identified from the KII and FGD, supported those discovered from the survey. $100 \%$ of the KII and FGD respondents rightly linked the cause to heat and dry season (weather).This demonstrates having the right perception of the predisposing factors which is in agreement to studies conducted by Abdussalam and Qaffas, (2016); NCDC (2017); Olowokure, (2006); and Scarborough and Thwaites (2008). Similar findings were found in studies in Burkina Faso (Colombini et al., 2011), Ghana (Hayden et al., 2013; Codjoe and Nabie, 2014); and Benin (Besancenot et al., 1997). Studies by Fone, (2003), and Stanwell-Smith et al., (1994), differed slightly in opinion, but are more or less in agreement. To buttress association of Meningitis with environmental features, areas outside Africa that share the environmental features of the meningitis belt such as Moscow, China, Nepal, and India, have also witnessed epidemics. These areas are also characterized by low humidity, as an extension of the $300-1100 \mathrm{~mm}$ mean rainfall isohyets across the world, (Cuevas et al., 2007).

The identified predisposing factors can be summed up into weather related and socio-economic factors. Knowledge of these factors would help advance dynamic vaccine development and distribution.

\section{Socioeconomic Impacts of Meningitis}

Meningitis leaves behind severe consequences wherever and whenever it occurs. In this research, findings revealed that loss of lives (mortality), economic burden, permanent disability (morbidity); and impoverishment and loss of productivity were the top most consequences of Meningitis with mortality and morbidity topping the list which agreed with findings of earlier studies done by Abdussalam and Qaffas, (2016), and Mohammedet al., (2000), which reported that Nigeria alone lost over 22,664 deaths between 1991 and 2011, and more recently, 1,166 lives in 2017 (NCDC, 2017; NCDC, 2018).

Here also, there was no particular pattern or relationship observed between variables like sex, age, geographical focus and level of education, with the socioeconomic factors, when cross tabbed, for the same likely reason of allowing multiple responses for respondents which were ranked according to the frequencies observed.

Similarly, $100 \%$ of the KII and FGD respondents mentioned morbidity and mortality as first impact. $50 \%$ of rural and $20 \%$ of urban FGD respondents talking from experience, attested having witnessed firsthand impairments of learning difficulties, sight, hearing, and behavioral problems in their children, relatives and neighbors, in accordance to the 
findings of Hoogman et al., (2007), Meli et al., (2002), and Van de Beek et al., (2002). Meningitis causes economic burden and contributes to the cycle of poverty (impoverishment). No country specific data exists but studies by Hayden et al., (2013); and MenAfriNet, (2018), revealed that each case of meningitis treatment in a family in Burkina Faso results in loss of $\$ 90$ which is 3 or 4 times the monthly income of the family. Also revealed by this research is that Meningitis causes low productivity and school drop outs quantified as DALYS. Meningitis was responsible for 891 DALYs recorded in Africa in 2002 by WHO (Bloom et al., 1998). Creation of chaos in the health system is not left out as revealed by participants in the FGD; which agrees with findings by Colombini et al., (2011). The socio-economic impacts can also be summed up into health related and socioeconomic factors.

A closer look at the responses on predisposing factors and socio-economic impacts revealed similarity and association in the responses which is in the area of socio-economic factors. There is association between poverty as a predisposing factor and impoverishment as a socioeconomic impact. The poverty level prevalent in sub-Saharan Africa (inclusive of Nigeria), is a huge factor which impacts negatively on the management of Meningitis through the existence of poor housing facilities with poor ventilation, overcrowding, poor environmental sanitation, very low per capita income (less than $\$ 1$ dollar a day) to mention but a few (Gudina et. al., 2016; NCDC, 2017). In Nigeria, more than 100 million live on less than USD 1 per day (NBS, 2012). This level of poverty will obviously affect the quality of lives of the citizens thereby enhancing existence and spread of Meningitis, and this will in turn impact the socio-economic lives of the populace in that, the high out of pocket expenditure, due to poor health funding, will lead to further impoverishment of the already poor populace. This forms acycle as discovered by Hayden $e t$ al., (2013); and MenAfriNet, (2018), which cited an example with Burkina Faso where each case of Meningitis treatment in a family in Burkina Faso results in loss of $\$ 90$ which is 3 or 4 times the monthly income of the family.

The impoverishment equally plays a part in the ability to afford good housing with attendant spacing, ventilation and sanitation. This is evidenced by the identified overcrowding, poor sanitary condition and poor housing as predisposing factors which will lead to economic burden as an impact because these factors in themselves predispose to Meningitis which when treated out of pocket as in many cases leaves a huge financial burden on those affected.

There is also an association between infection as a predisposing factor and morbidity, loss of productivity, and increased rate of malnutrition as mentioned in the socioeconomic impacts. Meningitis itself is an infection affecting mostly children, hence a child that is suffering from Meningitis in an impoverished family will likely not be well fed leading to malnutrition. Poverty will also cause delay in accessing care, leading to late presentation and ultimately morbidity or mortality. Loss of productivity occurs when parents and care givers miss work due to ill health or to care for the sick child, as well as the child missing out on his/her schooling.

Poor risk communication as identified as a predisposing factor also influences occurrence of stigma and discrimination, recognized as an impact, which most often occurs due to poor/lack of understanding of the disease in occurrence.

\section{CONCLUSIONS}

Meningitis is an airborne microbial infection that is difficult to prevent due to the multifaceted predisposing factors involved in itsoccurrence especially the weather-related elements. Historically, Meningitis has been the cause of mass mortalities and morbidities aside the economic impact on individuals, families, communities and country at large. Due to multiplicity of factors, the tendency of eradicating Meningitis is minimal but it can be eliminated when the multifaceted factors are addressed. Mortalities / morbidities are very big burdens of Meningitis in addition to other socioeconomic impacts.

In Nigeria, the predisposing factors of Meningitis were identified mainly as overcrowding, poor sanitary condition, weather, and poverty (weather related and socio-economic factors), leading to loss of lives (mortality), economic burden, permanent disability (morbidity); and impoverishment and loss of productivity (health related and socio-economic factors). These are all interrelated and forms a viscous cycle detrimental to health and well-being of Nigerians. Aside the weather elements which are natural, other factors can be influenced positively by improved economic wellbeing, public enlightenment and better healthcare.

The study discovered that the respondents had the right understanding of the predisposing factors which can be leveraged on for effective risk communication, and management. Understanding these trends and factors would help develop effective surveillance and early warning systems as well as effective vaccine distribution to mitigate the negative impacts of the disease.

\section{ACKNOWLEDGEMENT}

The research team will like to thank all the participants for their participation and cooperation.

\section{REFERENCES}

[1] Abdussalam, A. F., and Qaffas, F. (2016) 'Spatiotemporal patterns and social risk factors of Meningitis in Nigeria', Open Access Library Journal, 3:e2909; available at http://dx.doi.org/10.4236/oalib.1102909; accessed 13 May, 2018.

[2] Besancenot, J.P., Boko, M., and Oke, P.C. (1997) 'Weather conditions and cerebrospinal meningitis in Benin (Gulf of Guinea, West Africa)' European journal of epidemiology, 13 (7): 807-15, Oct. 1997.

[3] Bloom, D E., Sachs, J. D., Collier, P., and Udry, C. (1998) 'Geography, demography, and economic growth in Africa', Brookings Papers on Economic Activity, 2 (1998): 207-95.

[4] Codjoe, S.N.A., and Nabie, V.A. (2014) 'Climate change and 
Cerebrospinal Meningitis in the Ghanaian Meningitis belt' Int J Environ Res Public Health. 2014 Jul; 11(7): 6923-6939; available at https://www.ncbi.nlm.nih.gov/pmc/articles/PMC4113853/; accessed 20 April 2018

[5] Colombini, A., Badolo, O., Gessner, B. D., Jaillard, P., Seini, E., and Da Silva, A. (2011) 'Costs and impact of meningitis epidemics for the public health system in Burkina Faso', Vaccine, 29 (33) : 5474-5480; 26 July 2011

[6] Cuevas, L.E., Jeanne, I., Molesworth, A., Bell, M., Savory, E.C., Connor, S.J., and Thomson, M.C. (2007) 'Risk mapping and early warning systems for the control of Meningitis in Africa', Vaccine $25 S$ (2007) A12 - A17; 3 September; available at file://C:/Users/NNAJI\%20AZUKAEGO/Downloads/Cuevasrisk mappingmeningitisVaccine.pdf; accessed 1 July 2018. Doi:10.1016/j.vaccine.2007.04.034

[7] Fone, D. L., Harries, J. M., Lester, N., and Nehaul, L. (2003) 'Meningococcal disease and social deprivation: a small area geographical study in Gwent, UK.', Epidemiology and infection, 130 (1) : 53-8, Feb. 2003.

[8] Gudina, E. K., Tesfaye, M., Adane, A., Lemma, K., Shibiru, T., Pfister, H., and Klein, M. (2016) 'Challenges of bacterial meningitis case management in low income settings: an experience from Ethiopia', Tropical Medicine and International Health, 21 (7): 870-878, July 2016.

[9] Hayden, M.H., Dalaba, M., Awine, T., Akweongo, P., Nyaaba, G., Anaseba, D., Pelzman, J., Hodgson, A., and Pandya, R. (2013) 'Knowledge, attitudes, and practices related to Meningitis in northern Ghana', Am. J. Trop. Med. Hyg., 89(2): 265-27; 2013.

[10] Hoogman, M., Van de Beek, D., Weisfelt, M., De Gans, J., and Schmand, B. (2007) 'Cognitive outcome in adults after bacterial Meningitis' J Neurol Neurosurg Psychiatry 2007; 78:1092-1096.

[11] Jafri, R. Z., Ali, A., Messonnier, N. E., Tevi-Benissan, C., Durheim, D., Eskola, J., Fermon, F., Klugman, K.P., Ramsay, M., Sow, S., Zhujun, S., Bhutta, Z. A., and Abranson, J. (2013) 'Global epidemiology of invasive meningococcal disease' Population Health Metrics, 11:17; available at https://www.ncbi.nlm.nih.gov/pmc/articles/PMC3848799/pdf/147 8-7954-11-17.pdf; accessed 10 April 2018.

[12] Meli, D.N., Christen, S., Leib, S.L., and TaĖuber, M.G. (2002) 'Current concepts in the pathogenesis of Meningitis caused by Streptococcus pneumonia' Current Opinion in Infectious Diseases 2002, 15:253-257.

[13] MenAfriNet, (2018) 'Impact of Meningitis epidemics in Africa'; available at http://www.menafrinet.org/enus/What/Meningitis/Epi/Impact; accessed 10 May 2018.

[14] Mohammed, I., Nasidi, A., Alkali, A. S., Garbati, M. A., AjayiObe, E. K., Audu, K. A., Abdulmumini Usman, A., and Abdullahi, S. (2000) 'A severe epidemic of meningococcal
Meningitis in Nigeria, 1996' Transactions of The Royal Society of Tropical Medicine and Hygiene, 94 (1): 265-270, May 2000; available at https://doi.org/10.1016/S0035-9203(00)90316-X. abstract; accessed 2 August 2018.

[15] NBS (2012); National Bureau of Statistics; available at http://www.nigerianstat.gov.ng/; accessed 10 May 2018.

[16] NCDC (2017) 'First annual report of the Nigeria Centre for Disease Control (August 2016 - July 2017)'; available at http://www.ncdc.gov.ng/themes/common/docs/protocols/78_1515 412191.pdf; accessed 20 April 2018

[17] NCDC (2018) Situation Report 'An update of meningitis outbreak in Nigeria for weeks 14

[18] NCDC (2019) Situation Report 'An update of meningitis outbreak in Nigeria for week 23,

[19] NPC (2018); Nigerian Population Council; available at http://population.gov.ng/; accessed 20 April 2018.

[20] Ogundipe, S., and Obinna. C. (2017) Meningitis: What every Nigerian should know'; available at https://www.vanguardngr.com/2017/04/meningitis-everynigerian-know/; accessed 13 January 2018.

[21] Olowokure, B., Onions, H., Patel, D., Hooson, J., and O’Neill, P. (2006) 'Geographic and socioeconomic variation in meningococcal disease: a rural/urban comparison', The Journal of infection, 52 (1): 61-6, Jan. 2006.

[22] Scarborough, M., and Thwaites, G. E. (2008) 'The diagnosis and management of acute bacterial meningitis in resource-poor settings', Lancet Neurol 2008: 7: 637-648.

[23] Stanwell-Smith, R. E., Stuart, J. M., Hughes, A. O., Robinson, P., Griffin, M. B., and Cartwright, K. (1994) "Smoking, the environment and meningococcal disease: a case control study" Epidemiology and infection, 112 (2): 315-28; Apr. 1994.

[24] Umaru, E. T., Ludin, A.N.M., Majid, M.R., Sabri, S., Moses, C., Enegbuma, W., and Abdrazack, N. T (2013) 'Risk factors responsible for the spread of meningococcal Meningitis: A review' International Journal of Education and Research, 1 (2) February 2013.

[25] Van de Beek, D., Schmand, B., De Gans, J., Weisfelt, M., Vaessen, H., Dankert, J., and Vermeulen, M. (2002) 'Cognitive impairment in adults with good recovery after bacterial Meningitis' The Journal of Infectious Diseases 2002;186:104752.

[26] WHO (2010) Managing Meningitis epidemics in Africa: A quick reference guide for health authorities and health-care workers, Geneva: WHO Document Production Services, Geneva, Switzerland; available at http://apps.who.int/iris/bitstream/handle/10665/70599/WHO_HSE _GAR_ERI_2010.4_eng.pdf; accessed 14 April 2018. 